\title{
The Chronological Factor in Understanding the Middle and Upper Paleolithic of Eurasia
}

\author{
by Katerina Douka and Tom Higham
}

\begin{abstract}
For more than half a century, prehistorians have grappled with radiocarbon-based chronologies that are often contradictory and imprecise. Several key debates in the Paleolithic have their roots, at least partially, in basic issues of chronology. When did Neanderthals disappear? When did Homo sapiens disperse across Eurasia? How long was the overlap among several hominin groups? Without reliable time control, these questions are unanswerable, and unravelling the Paleolithic remains a distant and virtually unachievable goal. It is only recently that the extent of the problems with the application of radiocarbon dating near the limit of the method has become understood. Major challenges have arisen, ranging from inadvisable and poor selection of samples, on the one hand, to the analytical, chemical, and instrumental challenges of dating the low amounts of residual radiocarbon in these samples, on the other. Recent work has led to significant developments in the field. In this paper, we briefly review some of these developments, drawing on recent work undertaken at two sites, Bondi Cave (Georgia) and Kostenki 14 (Russia). By comparing new radiocarbon determinations against previous results, it is possible to begin to quantify quite how erroneous some of the previous chronometric models were.
\end{abstract}

The Middle to Upper Paleolithic transition, dating broadly to between 50,000 and 30,000 years BP, marks a pivotal point in late human evolution. In Europe and western Asia, it involves the latter stages of the dispersal of anatomically and behaviorally modern humans (AMH) outside of Africa, the replacement of Neanderthal populations, and the emergence of what is widely termed as the Upper Paleolithic - a period often associated with novel, symbolically loaded artifacts suggested to represent an important change in the cognitive abilities of modern humans (e.g., Bar-Yosef 2002; Klein 1995; Mellars 1989, 1991, 2005). Other authors have pointed out the occurrence of such artefacts in Africa much earlier (McBrearty and Brooks 2000) and the possible production of symbolic artefacts by European Neanderthals (e.g., Zilhão et al. 2010), yet the latter is not a universally accepted behavioral trait.

Similar - but not identical - processes affect Central and East Asia (and Australasia), leading to the wider establishment of AMH from the tropical rainforests of Sri Lanka and Thailand

Katerina Douka is a Group Leader at the Max Planck Institute for the Science of Human History (Kahlaische Strasse 10, D-07743 Jena, Germany) and a Visiting Academic in the Research Laboratory for Archaeology, University of Oxford (1-2 South Parks Road, Oxford OX1 3TG, United Kingdom [katerina.douka@rlaha.ox.ac.uk]). Tom Higham is Professor of Archaeological Science and Deputy Director of the Oxford Radiocarbon Accelerator Unit, Research Laboratory for Archaeology and the History of Art, University of Oxford (1-2 South Parks Road, Oxford OX1 3TG, United Kingdom [thomas.higham@rlaha .ox.ac.uk]). This paper was submitted 12 X 16, accepted 15 VI 17, and electronically published 24 X 17. to the Siberian steppes and from the arid plains of Uzbekistan to the savanna of the Australian Northern Territory. However, the situation in this part of the world is far more complex, given the presence of archaic humans living in the continent (Denisovans, Homo floresiensis, possible late Homo erectus, and archaic Homo sapiens). These humans, we now know, have coexisted and in some cases interbred with incoming $\mathrm{AMH}$, leading to a degree of genetic and potential cultural mixing.

So far, the vast majority of archaeological and chronometric research concerned with the Middle to Upper Paleolithic transition outside Africa has largely focused on one particular area: western Europe. Elsewhere, and possibly with the exception of Australia, not only is the archaeological record less abundant, but chronometric data are often minimal or absent.

Asia is critical to human evolution, particularly because AMH leaving Africa appear to have initially dispersed there before moving onward to Europe, Australia, and the Americas. Exciting new evidence is just beginning to rival in importance the better-known paleoanthropological records of longer- and better-investigated regions of Europe and Africa. The identification of Neanderthal presence beyond Europe and well into Siberia (Krause et al. 2007), along with growing fossil and archaeological evidence for the possible presence of $\mathrm{AMH}$ in China earlier than originally thought (e.g., Liu et al. 2015, but see also Michel et al. 2016), as well as confirmation that incoming $\mathrm{AMH}$ admixed genetically with indigenous archaic Asian populations (Fu et al. 2014; Green et al. 2010), reveals the Late Pleistocene record of human evolution to be much more complex than previously recognized. Most surprising has been the discovery, in 2010, of a new human group, the Denisovans, 
known almost exclusively from the genomic sequencing of DNA and four tiny bone fragments recovered at the eponymous cave site in southern Siberia. The lack of significant Denisovan remains has been seen as a paradox and has led to them being referred to in the popular science press as the "genome in search of a fossil."

Despite the importance of these recent findings, our understanding of archaic human presence in continental Asia remains unclear and lags behind information collected and synthesized from other continents. Among the reasons for this lag are the difficulties encountered so far, at a continental scale, in the recovery and identification of well-excavated and fully analyzed archaeological sites containing in situ fossils. One important component within this uncertainty is the lack of a reliable chronology, the challenge in directly dating precious human fossils, and the difficulty in comparing dates of specific lithic traditions across space. This paper outlines how novel chronometric developments and approaches offer the opportunity to improve this situation significantly.

\section{Approaches in Chronology Building}

Radiocarbon $\left({ }^{14} \mathrm{C}\right)$ dating is the most widely used scientific methodology for absolute dating of archaeological remains. Its effective limit, $\sim 50,000$ years ago, means that most significant events of late human evolution can be directly dated. The use of accelerator mass spectrometry (AMS) for the measurement of the residual ${ }^{14} \mathrm{C}$ in a sample also means that very small samples (between 0.5 and $2 \mathrm{mg}$ of carbon) can be measured. There are three principal areas of development one can trace over the past 10-15 years. First, there have been several technical improvements, including higher measurement precision, lower backgrounds in particle accelerators, and more accurate subtraction of laboratory-derived ${ }^{14} \mathrm{C}$ backgrounds using sample-specific standards (Bronk Ramsey, Higham, and Leach 2004; Wood, Bronk Ramsey, and Higham 2010). To reach 50,000 BP, a measurement precision of $\pm 0.1 \%$ is required. Before the mid-2000s, this was not achievable, and therefore the maximum age limit broached 40,000 BP or younger in some laboratories. Second, a calibration curve that stretches back to the limit of radiocarbon (the latest iteration is Reimer et al. 2013) not only allows calibration into sidereal time but offers the opportunity of building Bayesian age models, incorporating results from other dating techniques, and enabling tentative comparison against climate records, such as those from the Greenland ice cores (e.g., Andersen et al. 2006). It was not possible to do this with confidence until as late as 2009, when the first internationally agreed-upon 50,000-year-long calibration curve became available (Reimer et al. 2009). Third, significant improvements in chemical pretreatment and sample decontamination have resulted in superior purification of bone proteins, shell carbonates, and charcoal samples, which are the main items targeted for dating during this period. This has led to an increasing number of samples predating $40 \mathrm{ka} \mathrm{BP}$ and being reproducible at that age. In this paper, we examine the effects of sample decontamina- tion and the application of Bayesian statistics in the chronostratigraphy of two Paleolithic sites in Russia and Georgia.

The radiocarbon dating of old ( $>10-\mathrm{ka})$ samples has proven to be particularly challenging for the radiocarbon community. Contamination with external carbon from modern or quasimodern sources will alter a radiocarbon age by hundreds or sometimes thousands of years. It is well known, for example, that a sample whose actual age is 30,000 years, will, if contaminated with $2 \% \mathrm{C}$ of modern origin, return an AMS measurement 5,000 years too young. A sample with a "true" age of 40,000 years, with the same amount of unremoved carbon contamination, will return an age of $29 \mathrm{ka}$, which is 11,000 years too young. For this reason, chemical protocols aiming at removing exogenous carbon from a sample before AMS dating are constantly being developed and improved to minimize and reduce the effect of contamination.

When dating bones, the organic fraction (collagen), rather than the diagenesis-prone inorganic matrix, is extracted and analyzed. In the early 2000s, the development and broader application of ultrafiltration as an additional step in the radiocarbon dating of Paleolithic-age bone (based on Bronk Ramsey et al. 2004; Brown et al. 1988; Higham, Jacobi, and Bronk Ramsey 2006) significantly improved our ability to purify collagen on a routine basis. An ultrafilter is a molecular sieve that separates high from low molecular weight fractions of the collagen. Highmolecular-weight components will include nondegraded collagen, while low-molecular-weight components, which may contain degraded amino acids and peptides as well as soil-derived particles, all of which may be contaminants, are discarded. When ultrafiltration is applied to Pleistocene-age bones, it produces dates that are more reliable and often older than previous measurements. In addition, the extracted bone collagen is improved in terms of quality. In previously published work (e.g., Higham 2011; Higham et al. 2014), we have found that between $70 \%$ and $100 \%$ of previously obtained radiocarbon results were inaccurate after the same sites were reanalyzed using the ultrafiltration protocol. The new results are more consistent with site stratigraphies and have often changed significantly our understanding about human presence and occupation patterns at a site and a region as a whole.

For highly contaminated bones, even more stringent methodologies are currently being developed, tested, and applied to ensure contaminant-free radiocarbon dates. An advanced method involves extracting single amino acids from bones using highperformance liquid chromatography (HPLC). This technique ensures that the measured carbon comes only from the collagen amino acids and no other external contaminants. We have applied single amino acid dating to highly contaminated human bones from two key Mid-Upper Paleolithic sites in Russia, at Sungir and Kostenki 14 (Marom et al. 2012). These are two important burial sites of AMH that had not been dated reliably due to contamination of the bones with organic preservatives while in museum storage. The Kostenki 14 skeleton was previously dated three times (Hoffecker 2011; Sinitsyn 2004), but all determinations were much younger than anticipated $(\sim 3,700$, 
4,700, and 13,600 BP), leading to serious doubts over whether the specimen was actually Paleolithic. Krause et al. (2010) obtained a complete mitochondrial DNA genome from the skeleton, but no new dating was forthcoming because of the contamination present in the sample. Instead of trying to date bulk collagen, in 2012, members of our team extracted and purified the single amino acid hydroxyproline (HYP) from the tibia of the specimen and obtained a date of 33,250 $\pm 500 \mathrm{BP}$ (Marom et al. 2012). This age is much older than the previous contaminated measurements and consistent with the stratigraphic position of the burial in the Kostenki 14 site, as we show below, making it the earliest directly dated modern human associated with a secure archaeological context anywhere in Eurasia. Isolation and dating of a single amino acid guarantee that there is no interfering contamination and are essentially a "gold standard" ${ }^{14} \mathrm{C}$ measurement.

The Sungir case disclosed a similar result. Previously, the Sungir double burial and the remains of Sungir 1, an older male, were radiocarbon dated with less robust methods (Dobrovolskaya, Richards, and Trinkaus 2011; Kuzmin et al. 2004; Pettitt and Bader 2000) that produced results that were at odds with the archaeological evidence, which suggests that the individuals probably died at the same time. New radiocarbon HYP results, however, produced a series of dates that were not only significantly older but also consistent and statistically identical (Marom et al. 2012, 2013). In the future, it will be very important to apply these types of methods to problematic cases; important human fossils, such as in the recent case of the Vindija Neanderthal fossils (Devièse et al. 2017); and low-collagen bones, which have usually proven impossible to date so far.

Other dating materials have also seen developments and significant improvements. Charcoal samples may now be pretreated using rigorous acid-base oxidation followed by stepped combustion (ABOx-SC) methods (Bird et al. 1999; Wood et al. 2012 and references therein). Like ultrafiltration, the new charcoal protocols remove organic contaminants from the samples and have led to significant revisions of previously established chronologies. We have spearheaded the application of this technique to the European Paleolithic record-for example, in sites in Russia (Douka et al. 2010) and Italy (Brock and Higham 2009; Wood et al. 2012) — and have demonstrated its applicability to cold, temperate, and tropical environments (e.g., Higham et al. 2009; Sutikna et al. 2016).

When archaeological sites and materials are near to or beyond the limit of radiocarbon $(>50 \mathrm{ka}$ ) or where organics preservation is poor, optically stimulated luminescence (OSL) and infrared-stimulated luminescence (IRSL) dating of sediments can provide the best means of establishing a chronological framework. OSL and IRSL dating offer an estimate of the time since grains (usually on quartz or feldspar, respectively) were last exposed to sunlight. These methods can routinely measure the age of sediments from 0-200,000 years of age, but the upper limit (lower or much higher) varies locally, because it depends on the rate of saturation of the luminescence signal with dose. It is crucial that, at a broad timescale and when a site is occupied over a long period of time, multiple methods are adopted. A good example of what is possible is provided by recent work at the site of Haua Fteah in Libya (Douka et al. 2014), where a suite of different chronological methodologies $\left({ }^{14} \mathrm{C}\right.$, OSL, tephra studies, and electron spin resonance) were used to build a reliable temporal framework for human occupation at the site covering the last 100,000 years.

Interpretation of the results of multiple methods of absolute dating like this is made possible by formal Bayesian statistical modeling. This approach has strengthened and formalized the interpretation of chronometric results by incorporating absolute data (e.g., the radiocarbon and luminescence measurements) with "prior" beliefs based on our knowledge of the archaeological site, information on the relative ordering of events, the position of a sample in the stratigraphy, and our estimated confidence in the dating results. Bayesian modeling provides the framework to help answer questions regarding the spatiotemporal relationships of hominin groups, the duration of overlap, the exact timing of their presence in an area, and the date of last appearance. Previous approaches, in which dates are compared "by eye," often increase the chances of interpretative errors involving the overestimation of temporal range due to problems decoding the natural statistical scatter of radiocarbon measurements and the influence of variations in the calibration curve. Bayesian modeling provides the mathematical and statistical framework for reliably interpreting chronometric data.

\section{Case Studies}

The impact of these new approaches to archaeological sites can be shown with recent work we have undertaken in Georgia at two Eurasian sites, Kostenki 14 (Markina Gora) in Russia and Bondi Cave in Georgia (fig. 1). The site of Bondi Cave documents a key period of the Middle to Upper Paleolithic sequence of the region (Tushabramishvili et al. 2012). The site is located in the Imereti region of northwestern Georgia (fig. 1) and comprises a well-stratified $>3$-m-thick late Pleistocene sequence. Layers VIII and VII, over $60 \mathrm{~cm}$ thick, are attributed to the Middle Paleolithic and are topped by a long Upper Paleolithic sequence that includes layers $\mathrm{V}$ to $\mathrm{I}$, about $150 \mathrm{~cm}$ thick. Layer VI, a level of ceiling fall debris block, separates the Middle Paleolithic and Upper Paleolithic sequences. The Upper Paleolithic part, and especially layers II, IV, and V, was the richest of the sequence. In earlier archaeological work, a partial human tooth was recovered from sublayer $\mathrm{Vb}$, which has been identified as Homo sapiens.

Previous radiocarbon determinations from the site have been obtained from two different laboratories (Saclay and Beta Analytic). These are shown calibrated in figure 2 in depth orderlayer VII is the oldest, and layer III is the youngest (after Tushabramashvili et al. 2012). One can immediately appreciate that there is a lack of coherence in the sequence, and the results are characterized by a great degree of variability (fig. 2).

The Middle Paleolithic level VII appears to date to $40-43 \mathrm{ka}$ cal BP, while the Upper Paleolithic levels seem to start after 


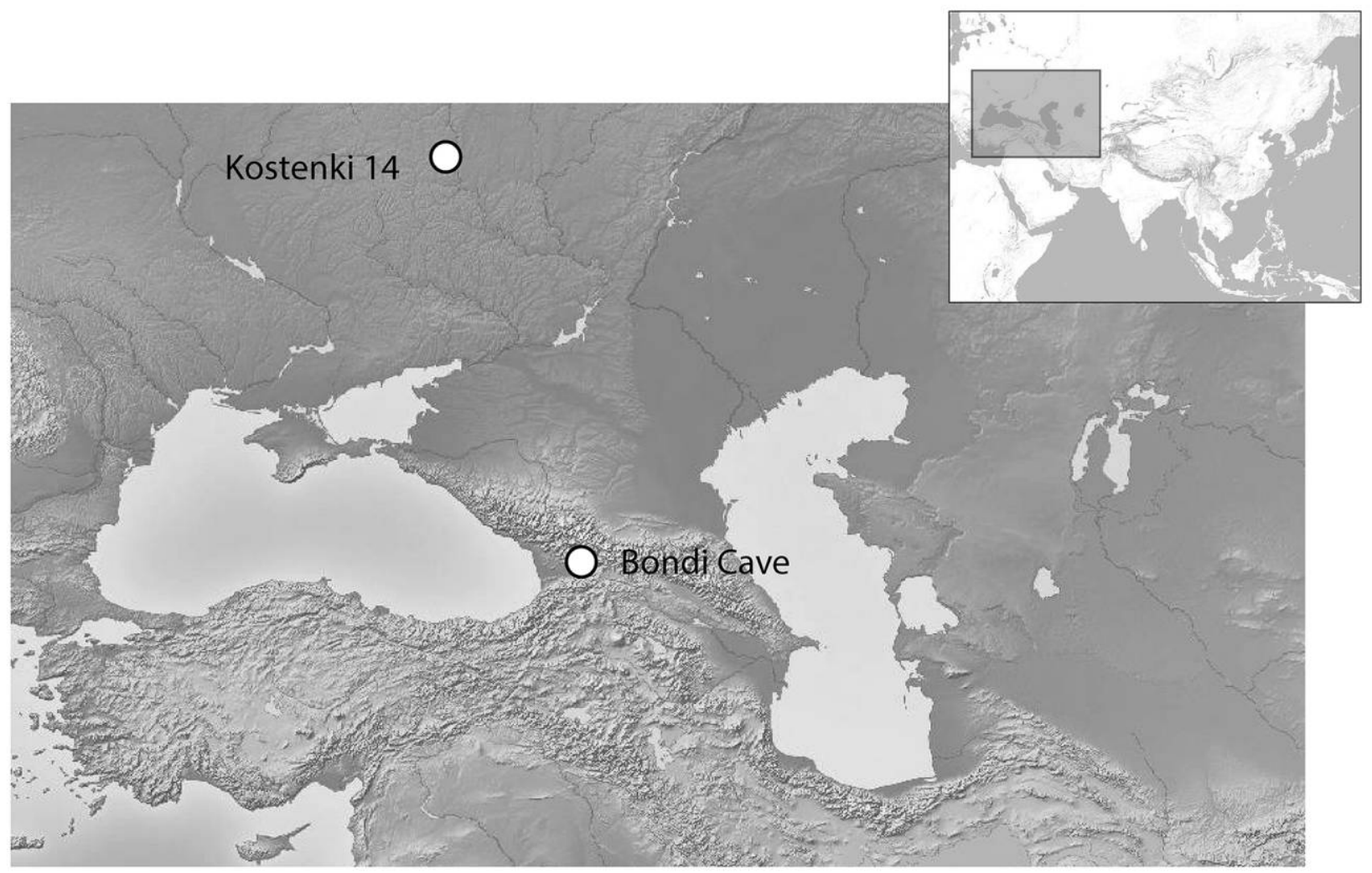

Figure 1. Map of northwest Asia showing the location of the two sites discussed in the text, Bondi Cave in Georgia and Kostenki 14 (Markina Gora) in Russia. A color version of this figure is available online.

$30 \mathrm{ka}$ cal BP. Layer VI is a distinct lithological phase representing roof collapse, and questions remain over whether it is an earlier Upper Paleolithic occupation dating to $35 \mathrm{ka}$ cal BP or if the Upper Paleolithic material it contains is intrusive from layer $\mathrm{V}$ above. Precisely why there appears to be much variation in the previous dates likely revolves around two possibilities. First, it could be due to stratigraphic mixing of material to a degree that was not identified in the excavation. This could also include the possibility that material selected for dating was not properly identified as being humanly modified and hence not certainly linked to human presence at the cave. Second, the results are due to incomplete decontamination and pretreatment chemistry of the samples. This is now an oft-repeated theme in the chronology of the Paleolithic (Higham 2011) in which we usually see underestimates of the real age of the materials.

To test these hypotheses, we obtained new samples of animal bone from the site. All samples selected were humanly modified (cut-marked or smashed during procurement) bones. Before collagen extraction and radiocarbon dating, we tested selected bones with percentage nitrogen methods (Brock, Higham, and Bronk Ramsey 2010) to ensure that they had sufficient remaining collagen for analysis. We selected 28 new samples from 8 layers and sublayers of the site. The samples were dated using ultrafiltration preparation in the Oxford Radiocarbon Accelerator Unit (ORAU).

We obtained 23 new AMS determinations. These new results suggest that the previous dates are indeed almost certainly significant underestimates. Samples from Middle Paleolithic layer VII, which were previously producing conventional radiocarbon ages of 35,000-37,000 BP (40,000-43,000 cal BP), were all greater than the radiocarbon age limit (i.e., >50,000 BP). Layer VI, which represents a major phase of cave collapse, previously dated at $32,000 \mathrm{BP}$, produced an age very close to the radiocarbon limit as well $(47,500 \pm 2,600 \mathrm{BP})$. All material from Middle Paleolithic layers VII/VIII, therefore, date to beyond 50,000 years ago. All of the AMS dates from Upper Paleolithic level $\mathrm{V}$ were consistent and produce results that span the period 40-37 ka cal BP. Here, too, they are much older than the previous chronology would suggest, by up to 10,000 years.

To properly interpret results such as these, it is crucial to use a Bayesian modeling approach, as described earlier. We used OxCal4.3 software (Bronk Ramsey 2009) and the INTCAL13 calibration curve (Reimer et al. 2013) to construct a statistical model for Bondi Cave (fig. 3). The model priors comprise the detailed evidence obtained from the excavation and the discrete layers and sublayers identified. The phases of each ex- 


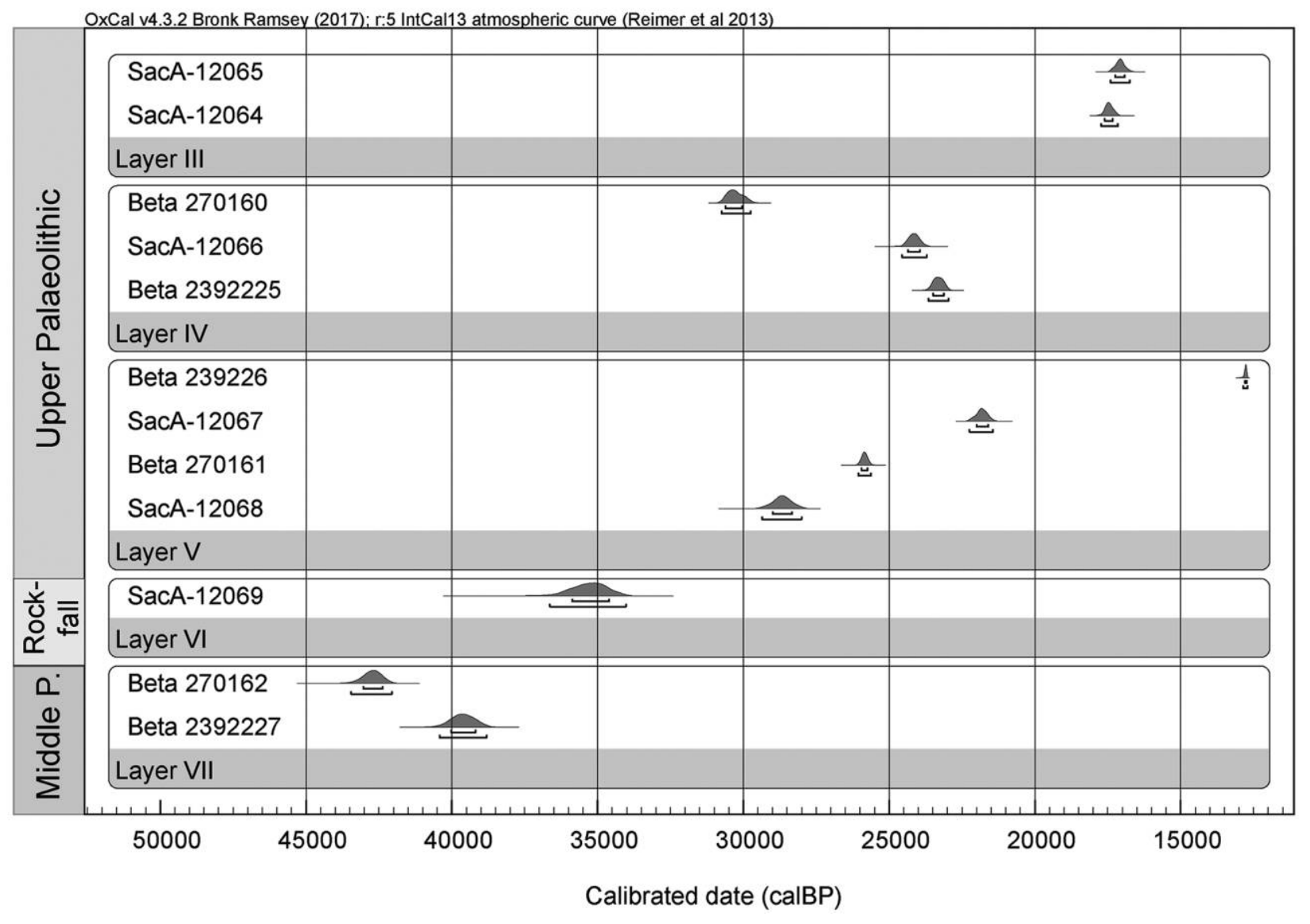

Figure 2. Previous radiocarbon chronology from the Bondi Cave site, from Tushabramashvili et al. (2012). The results show a great deal of variability and are therefore difficult to interpret. Middle P. = Middle Paleolithic. A color version of this figure is available online.

cavated layer contain the radiocarbon results obtained with no order assumed between them. Phases in sequence, from earliest to latest, are assumed to lie in order of stratigraphic superposition. The posterior results, from the output of the Bayesian modeling, are shown in the figure in darker outline. These suggest that the occupation of level V starts around 40,000 cal $\mathrm{BP}$ and ends by 33,000-34,000 cal BP. The results are in complete contrast to the previous chronology, and the data appear robust and reproducible, because there are no significant outliers identified in the sequence. Given our initial objective, to determine whether the chronological variability obtained in the previous series of dates was due to severe material mixing in the site's sequence or due to inadequate chemical pretreatment, we may now assume that the latter was the reason.

In addition, we can use this Bayesian age model as a means to estimate the age of material within different contexts in the sequence, even when such material is not directly dated. The human tooth, for instance, which was excavated in layer $\mathrm{Vb}$, can be estimated to date between 38,700 and 35,300 cal BP (95.4\%; see fig. 3), making it the earliest evidence for modern humans in the southern Caucasus mountain region. Such an estimate assumes no or very little postdepositional movement of material; given the consistency of the new dates from $\mathrm{Vb}$, as well as all other layers from Bondi Cave, we argue that this seems to be the case.

Another key advantage in using Bayesian approaches is the ability to integrate archaeological chronologies built from different radioisotopic and trapped-charge methods. We consider an example below from the site of Kostenki 14 (Markina Gora), one of the key sites in the Kostenki-Borschevo complex of sites in western Russia (fig. 1).

Kostenki 14 is an open-air site located on the west bank of the Don River, and most importantly for studies of the chronology of the site, it contains the Campanian Ignimbrite tephra, which lies in direct association with an Upper Paleolithic cultural horizon, the so-called "layer in volcanic ash" (LVA; Anikovich et al. 2007; Douka, Higham, and Sinitsyn 2010; Hoffecker et al. 2008; Sinitsyn 2003b). Although in parts of the site the tephra is clearly redeposited and subject to solifluction and slope movement, there are deposits that are considered to be in situ. LVA is considered to have been largely covered by the tephra fall and comprises typical Aurignacian lithic elements, including artefacts that evoke Roc de Combe twisted bladelets of the western European Aurignacian (Sinitsyn 2003a, 2003b). 
OxCal v4.3.2 Bronk Ramsey (2017); r.5 IntCal13 atmospheric curve (Reimer et al 2013)

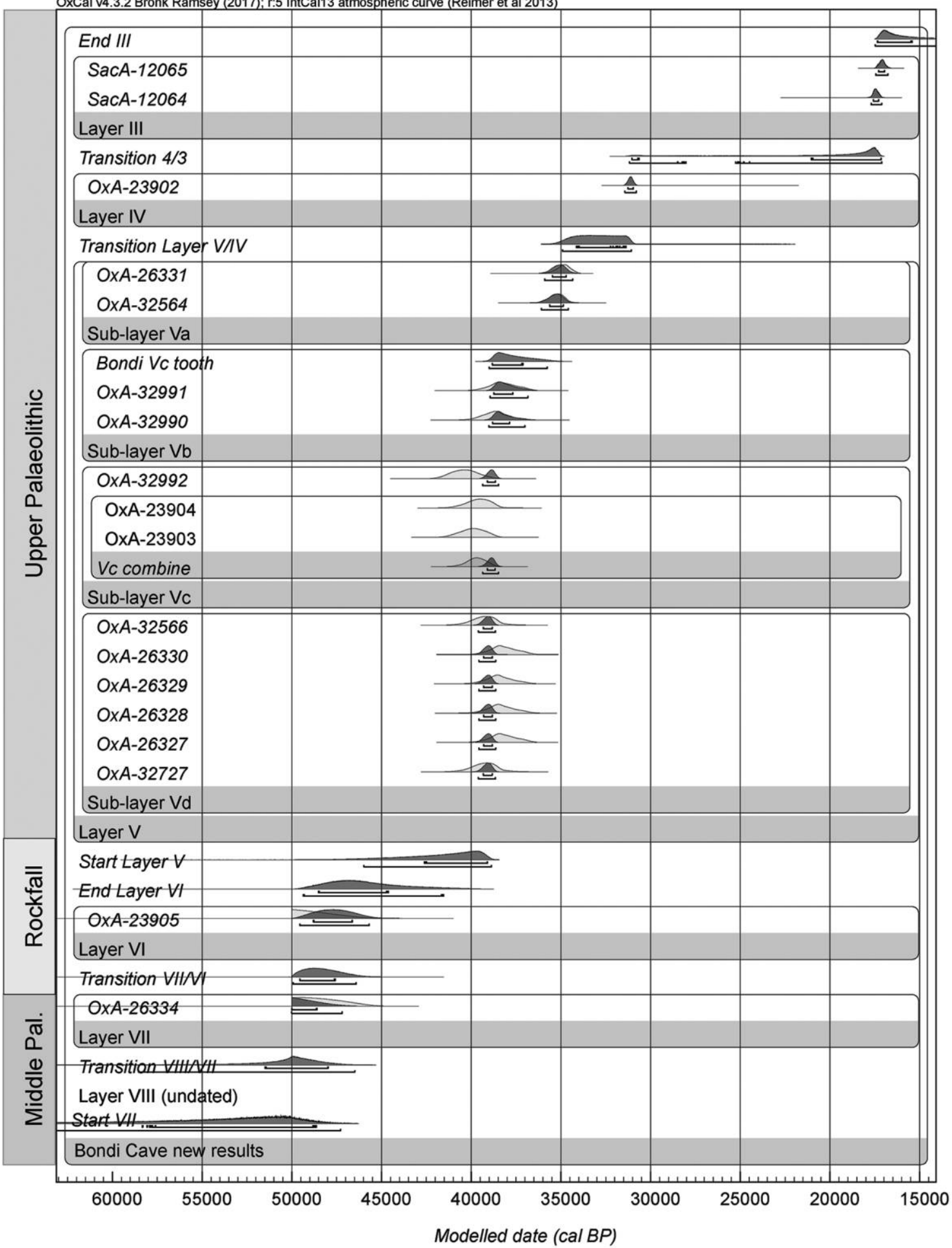

Figure 3. Bayesian age model for the site of Bondi Cave, Georgia. The model was produced using OxCal 4.3 (Bronk Ramsey 2009) and the INTCAL13 calibration curve (Reimer et al. 2013; for the data used in the model, see Pleurdeau et al. 2016). Middle Pal. = Middle Paleolithic. A color version of this figure is available online. 


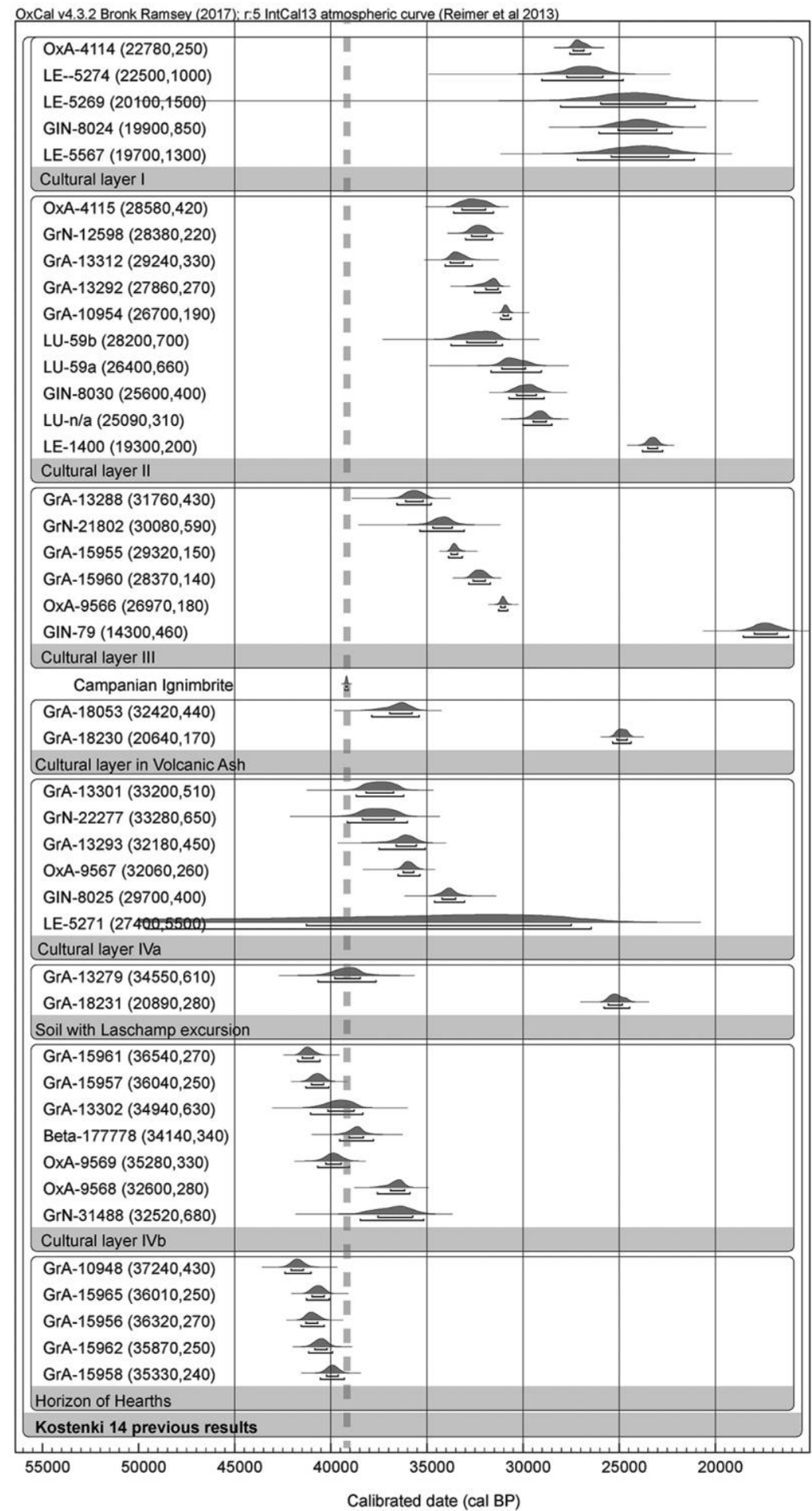

Figure 4. Previous radiocarbon chronology from Kostenki 14, based on the determinations published by Sinitsyn and Hoffecker (2006). The Campanian Ignimbrite is indicated in the sequence as a dashed gray line. It is clear that several results from layers superimposed by the tephra (layer in volcanic ash, IVa, and IVb) postdate the age of this marker by several millennia and hence must be considered erroneous. The ages for the lowermost cultural horizon, Horizon of Hearths, fall very close to the age of the tephra despite stratigraphic separation of the two horizons by as much $3 \mathrm{~m}$ at places. A color version of this figure is available online.

This content downloaded from 194.094.206.187 on November 02, 2017 05:20:50 AM 
Layers below this, including IVa and IVb, are of early Upper Paleolithic affinities; the latter, for instance, contains items of early human sculpture, decorated bone tools, and a fossil shell pendant of probable Mediterranean origin (Hoffecker et al. 2008; Sinitsyn 2003a).

Once again, serious problems have arisen in the previous radiocarbon dating of the sequence, with dates of bone and charcoal prepared using the routine acid-base-acid (ABA) protocol producing results inconsistent with the age estimate for the tephra fall and exhibiting serious variation (e.g., Giaccio et al. 2006; Haesaerts et al. 2004; Sinitsyn and Hoffecker 2006). In figure 4, 11 of the 17 dates coming from layers clearly superimposed by the tephra (LVA, IVa, and IVb) postdate the age of this independently dated marker. In addition, all results from the Horizon of Hearths, the lowermost cultural layer at the site, sit very close to the age of the tephra despite the fact that they were produced on material found stratigraphically much deeper, at least 1.5-3.0 m below the tephra.

Over the past 5 years, we have obtained several new AMS dates from the site using more robust methods of pretreatment chemistry than previously was the case. The results include ABOx-SC determinations on charcoal (Douka et al. 2010; Wood et al. 2012), determinations on skeletal material based on the single amino acid HYP method (Marom et al. 2012), and new ultrafiltered collagen results of bones collected at the site between 2009 and 2014.

We built a new Bayesian age model for Kostenki 14, including these recent radiocarbon results. In addition to the AMS determinations, we also included the Campanian Ignimbrite calendar age and four luminescence (IRSL) ages obtained previously from level IVa/b (see Hoffecker et al. 2008). The dates of the Campanian Ignimbrite deposits are well known and reliable, being based on a series of ${ }^{40} \mathrm{Ar} /{ }^{39} \mathrm{Ar}$ determinations on sanidine crystals obtained from proximal deposits of the ash with the age extrapolated to the Don River sites (Giaccio et al. 2017). In our age model, the estimated age of the Campanian Ignimbrite was based on a weighted average of these dates after De Vivo et al. (2001) and Rolandi et al. (2003; see Wood et al. 2012 for discussion), providing an age estimation of $39,180 \pm 45$ years (before 1950).

The model is shown in figure 5. A high level of agreement and consistency is attested by the fact that there are no outliers of statistical significance. There is strong agreement between the luminescence ages and the radiocarbon results, and the absolute methods sit closely with the estimated age for the tephra, too. Taken together, this allows us to be confident in diagnosing a precise age for the industries identified at Kostenki 14.

These case studies demonstrate what is possible if a concerted effort is made to use robust radiocarbon methods, combined with other dating techniques, such as luminescence dating, nested within a Bayesian framework. Such integrated approaches are all the more important when dating sites that lie near or beyond the limit of radiocarbon. This is often the case in Asian sites, where modern human presence has been now postulated to lie well beyond $50 \mathrm{ka}$ or much earlier (e.g., Liu et al. 2015), while other forms of archaic humans (Denisovans, Homo floresiensis) appear to lie beyond the working limit of radiocarbon (e.g., Sutikna et al. 2016).

Finally, the archaeogenetics revolution is also starting to impact chronology studies. It has been shown recently that molecular dating, in the form of a quantitative approach that calculates genetic separation times estimated from deeply sequenced human genomes, is in broad agreement with the direct dating of samples using radiometric methods (e.g., Fu et al. 2014; Moorjani et al. 2016). Incorporating this kind of information, stemming from fossil material beyond and within the radiocarbon timescale, in Bayesian models along with traditional chronometric data is sure to influence the future understanding of human presence and interaction of various hominin groups in Paleolithic Eurasia.

\section{Conclusions}

To understand the proper sequence and process of cultural development during the Middle and early Upper Paleolithic of Eurasia, it is crucial that prehistorians have chronometric control. In the past, dating material from late Pleistocene sites using the principal method, radiocarbon, has been challenging. A series of advances in measurement technology and pretreatment chemistry has seen significant improvement that points to a way forward. Additionally, the application of Bayesian methodologies provides a robust framework for integrating age determinations from different methods that allow for more refined chronometric data sets to be obtained.

In this paper, we have given two examples of the type of chronometric work that we hope will become routine in $\mathrm{Pa}$ leolithic archaeology. At Bondi Cave in Georgia, we demonstrated the significant changes that occurred to the understanding of the site's archaeological sequence when improved radiocarbon protocols were applied. Fossil remains within this sequence could be ascribed tentative age estimates, despite not being directly dated, with the help of Bayesian statistics. At the site of Kostenki 14 (Markina Gora), in Russia, we showed how age estimates obtained using different methods (radiocarbon and luminescence) could be incorporated into a single Bayesian age model and the precision that can accrue. Building age models across space and time will allow us to compare probability distributions for different archaeological technocomplexes and begin the task of exploring how these industries relate to one another. Desmond Clark (1979:7) wrote that, were it not for radiocarbon dating, "we would still be foundering in a sea of imprecisions sometime bred of inspired guesswork but more often of imaginative speculation." The "sea of imprecisions" has hampered Pleistocene archaeology more than that of any other period in the radiocarbon timescale, but this is now improving. Our task is now to roll out these methods to many more sites across Asia. 


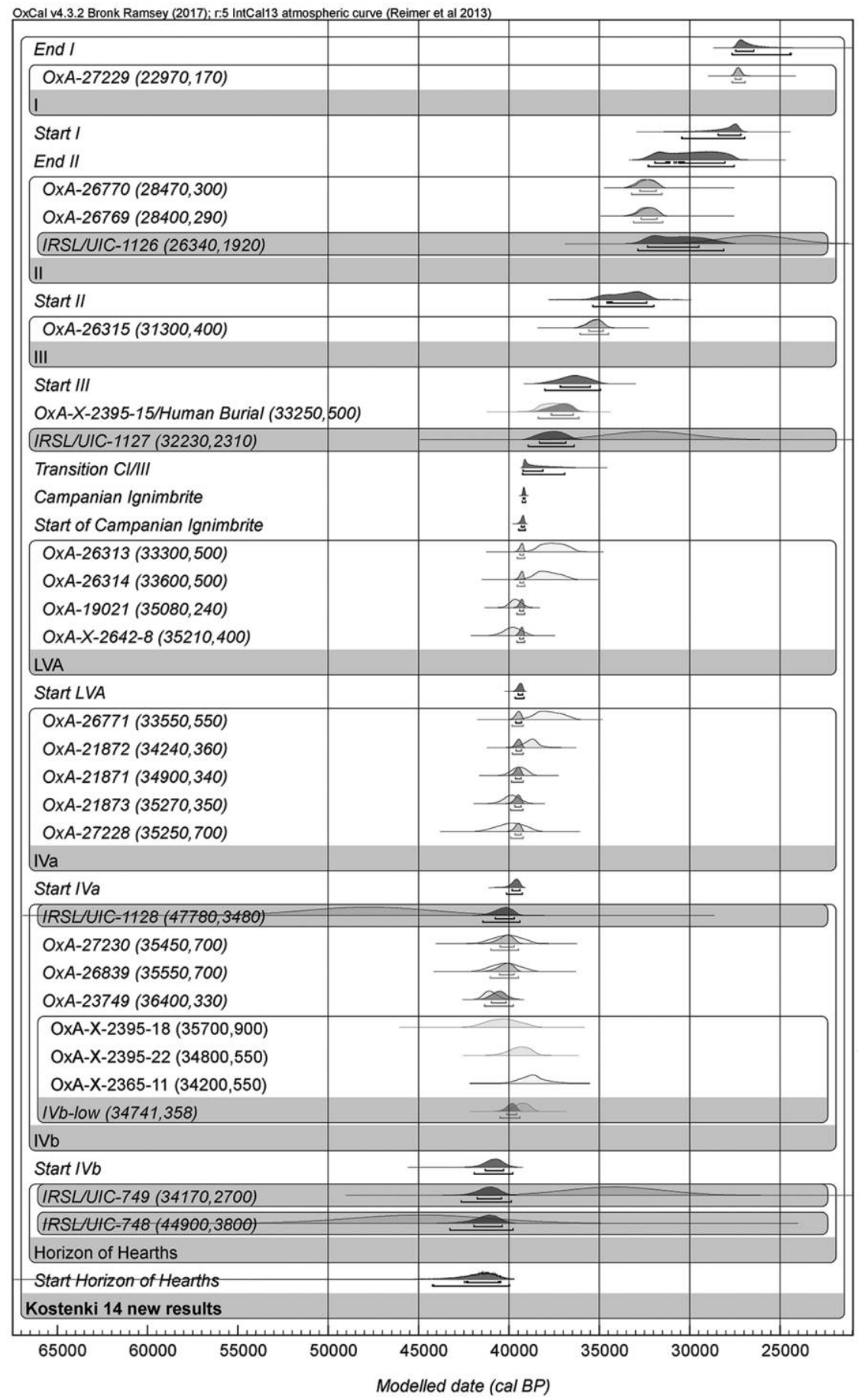

Figure 5. Age model for the Kostenki 14 sequence including only radiocarbon determinations prepared with the latest decontamination protocols as well as five infrared-stimulated luminescence (IRSL) dating ages. Bone dates of the amino acid hydroxyproline, probable dates based on ultrafiltered bone collagen, and acid-base oxidation followed by stepped combustion and alternative oxidase charcoal dates are shown in varying shades of gray. The IRSL ages are in a shaded dark gray border. The age of the Campanian Ignimbrite is input as a calendar date before 1950 based on the de Vivo et al. (2001) and Giaccio et al. (2017) estimates. There are no significant outliers in the model, and all radiocarbon age estimates (whether based on charcoal or bone) are consistent with the independently dated Campanian Ignimbrite tephra at the site. A color version of this figure is available online. 


\section{Acknowledgments}

This work received support from the Ancient Human Occupation of Britain (AHOB) 3 project, funded by the Leverhulme Trust, United Kingdom, and the European Research Council (ERC) under the European Union's Seventh Framework Programme (FP7/2007-2013)/ERC grant agreement 324139 "PalaeoChron," awarded to Professor Tom Higham. Katerina Douka has received funding from the ERC under the European Union's Horizon 2020 research and innovation program, grant agreement 715069-FINDER-ERC-2016-STG. We are grateful to Andrei Sinitsyn for allowing us access to the Kostenki 14 material and for Paul Haeseart's constructive discussions over the years. We thank Rod Dinnis and Chris Stringer for their help and support under the umbrella of the AHOB 3 project.

\section{References Cited}

Andersen, K. K., A. Svensson, S. J. Johnsen, S. O. Rasmussen, M. Bigler, R. Röthlisberger, U. Ruth, M.-L. Siggaard-Andersen, J. P. Steffensen, and D. Dahl-Jensen. 2006. The Greenland ice core chronology 2005, 15-42ka. Part 1: constructing the time scale. Quaternary Science Reviews 25(23-24): 3246-3257. doi:10.1016/j.quascirev.2006.08.002.

Anikovich, M. V., A. A. Sinitsyn, J. F. Hoffecker, V. T. Holliday, V. V. Popov, S. N. Lisitsyn, S. L. Forman, et al. 2007. Early Upper Paleolithic in eastern Europe and implications for the dispersal of modern humans. Science 315 (5809):223-226.

Bar-Yosef, Ofer. 2002. The Upper Paleolithic revolution. Annual Review of Anthropology 31(1):363-393. doi:10.1146/annurev.anthro.31.040402.085416. Bird, M. I., L. K. Ayliffe, L. K. Fifield, C. S. M. Turney, R. G. Cresswell, T. T. Barrows, and B. David. 1999. Radiocarbon dating of 'old' charcoal using a wet oxidation, stepped-combustion procedure. Radiocarbon 41(02):127140. doi:10.1017/s0033822200019482.

Brock, F., and T. F. G. Higham. 2009. AMS radiocarbon dating of Paleolithicaged charcoal from Europe and the Mediterranean rim using ABOx-SC Radiocarbon 51(2):839-846. doi:10.1017/s0033822200056149.

Brock, F., T. Higham, and C. Bronk Ramsey. 2010. Pre-screening techniques for identification of samples suitable for radiocarbon dating of poorly preserved bones. Lournal of Archaeological Science 37(4):855-865. doi:10.1016/j.jas.2009 .11 .015 .

Bronk Ramsey, C. 2009. Bayesian analysis of radiocarbon dates. Radiocarbon 51:337-360.

Bronk Ramsey, C., T. Higham, A. Bowles, and R. Hedges. 2004. Improvements to the pretreatment of bone at Oxford. Radiocarbon 46(1):155-163. doi:10.1017/s0033822200039473.

Bronk Ramsey, C., T. Higham, and P. Leach. 2004. Towards high-precision AMS progress and limitations. Radiocarbon 46(1):17-24. doi:10.1017/s0033822200 039308.

Brown, T. A., D. E. Nelson, J. S. Vogel, and J. R. Southon. 1988. Improved collagen extraction by modified Longin method. Radiocarbon 30(2):171177. doi:10.1017/s0033822200044118.

Clark, J. D. 1979. Radiocarbon dating and African prehistory. In Radiocarbon dating: proceedings of the Ninth International Conference, Los Angeles and La Jolla, 1976. R. Berger and H. E Suess, eds. Pp. 7-31. Los Angeles: University of California Press.

Devièse, T., I. Karavanić, D. Comeskey, C. Kubiak, P. Korlević, M. Hajdinjak, S. Radović, et al. 2017. Direct dating of Neanderthal remains from the site of Vindija Cave and implications for the Middle to Upper Paleolithic transition. Proceedings of the National Academy of Sciences of the USA 114 (40):10606-10611.

de Vivo, B., G. Rolandi, P. B. Gans, A. Calvert, W. A. Bohrson, F. J. Spera, and H. E. Belkin. 2001. New constraints on the pyroclastic eruptive history of the Campanian volcanic plain (Italy). Mineralogy and Petrology 73(1-3): 47-65. doi:10.1007/s007100170010.

Dobrovolskaya, M., M. P. Richards, and E. Trinkaus. 2011. Direct radiocarbon dates for the Mid Upper Paleolithic (eastern Gravettian) burials from
Sunghir, Russia. Bulletins et Mémoires De La Société d'Anthropologie De Paris 24(1-2):96-102. doi:10.1007/s13219-011-0044-4.

Douka, K., T. Higham, and A. Sinitsyn. 2010. The influence of pretreatment chemistry on the radiocarbon dating of Campanian Ignimbrite-aged charcoal from Kostenki 14 (Russia). Quaternary Research 73(3):583-587. doi:10 .1016/j.yqres.2010.01.002.

Douka, K., Z. Jacobs, C. Lane, R. Grün, L. Farr, C. Hunt, R. H. Inglis, et al. 2014. The chronostratigraphy of the Haua Fteah Cave (Cyrenaica, Northeast Libya). Journal of Human Evolution 66(1):39-63.

Fu, Q., H. Li, P. Moorjani, F. Jay, S. M. Slepchenko, A. A. Bondarev, P. L. F. Johnson, et al. 2014. Genome sequence of a 45,000-year-old modern human from western Siberia. Nature 514(7523):445-449. doi:10.1038/nature13810.

Giaccio, B., I. Hajdas, R. Isaia, A. Deino, and S. Nomade. 2017. High-precision $\mathrm{C}$ and ${ }^{40} \mathrm{Ar} /{ }^{39} \mathrm{Ar}$ dating of the Campanian Ignimbrite (Y-5) reconciles the time-scales of climatic-cultural processes at $40 \mathrm{Ka}$. Scientific Reports 7:45940. doi:10.1038/srep45940.

Giaccio, B., I. Hajdas, M. Peresani, F. G. Fedele, and R. Isaia. 2006. The Campanian Ignimbrite tephra and its relevance for the timing of the Middle to Upper Paleolithic shift. In When Neanderthals and modern humans met. N. J. Conard, ed. Pp. 343-375. Tübingen Publications in Prehistory. Tübingen, Germany: Kerns.

Green, R. E., J. Krause, A. W. Briggs, T. Maricic, U. Stenzel, M. Kircher, N. Patterson, et al. 2010. A draft sequence of the Neandertal genome. Science 328(5979):710-722.

Haesaerts, P., F. Damblon, A. Sinistyn, and J. Van der Plicht. 2004. Kostienki 14 (Voronezh, Central Russia): new data on stratigraphy and radiocarbon chronology. In The Upper Palaeolithic: proceedings of XIV UISPP Congress. M. Dewez, P. Noiret, and E. Teheux, eds. Pp. 169-180. Oxford: British Archaeological Reports, International Series 1240.

Higham, T. 2011. European Middle and Upper Palaeolithic radiocarbon dates are often older than they look: problems with previous dates and some remedies. Antiquity 85(327):235-249. doi:10.1017/s0003598x00067570.

Higham, T., H. Barton, C. S. M. Turney, G. Barker, C. Bronk Ramsey, and F. Brock. 2009. Radiocarbon dating of charcoal from tropical sequences: results from the Niah Great Cave, Sarawak, and their broader implications. Journal of Quaternary Science 24(2):189-197. doi:10.1002/jqs.1197.

Higham, T., K. Douka, R. Wood, C. Bronk Ramsey, F. Brock, L. Basell, M. Camps, et al. 2014. The timing and spatiotemporal patterning of Neanderthal disappearance. Nature 512(7514):306-309.

Higham, T., R. M. Jacobi, and C. Bronk Ramsey. 2006. AMS radiocarbon dating of ancient bone using ultrafiltration. Radiocarbon 48(2):179-195. doi:10.1017 /s0033822200066388.

Hoffecker, J. F. 2011. The Early Upper Paleolithic of eastern Europe reconsidered. Evolutionary Anthropology: Issues, News, and Reviews 20(1):24-39. doi:10.1002/evan.20284.

Hoffecker, J. F., V. T. Holliday, M. V. Anikovich, A. A. Sinitsyn, V. V. Popov, S. N. Lisitsyn, G. M. Levkovskaya, G. A. Pospelova, S. L. Forman, and B. Giaccio. 2008. From the Bay of Naples to the River Don: the Campanian Ignimbrite eruption and the Middle to Upper Paleolithic transition in eastern Europe. Journal of Human Evolution 55(5):858-870. doi:10.1016/j.jhevol.2008 .08 .018 .

Klein, R. G. 1995. Anatomy, behavior, and modern human origins. Iournal of World Prehistory 9(2):167-198.

Krause, J., A. W. Briggs, M. Kircher, T. Maricic, N. Zwyns, A. Derevianko, and S. Pääbo. 2010. A complete mtDNA genome of an early modern human from Kostenki, Russia. Current Biology 20(3):231-236. doi:10.1016/j.cub.2009 .11 .068 .

Krause, J., L. Orlando, D. Serre, B. Viola, K. Prüfer, M. P. Richards, J.-J. Hublin, C. Hänni, A. P. Derevianko, and S. Pääbo. 2007. Neanderthals in Central Asia and Siberia. Nature 449(7164):902-904.

Kuzmin, Y. V, G. S. Burr, A. J. T. Jull, and L. D. Sulerzhitsky. 2004. AMS C age of the Upper Palaeolithic skeletons from Sungir site, Central Russian Plain. Nuclear Instruments and Methods in Physics Research Section B: Beam Interactions with Materials and Atoms 223-224:731-734. doi:10.1016/j.nimb 2004.04.135

Liu, W., M. Martinón-Torres, Y.-J. Cai, S. Xing, H.-W. Tong, S.-W. Pei, M. Jan Sier, et al. 2015. The earliest unequivocally modern humans in southern China. Nature 526(7575):696-699. doi:10.1038/nature15696.

Marom, A., J. S. O. Mccullagh, T. F. G. Higham, and R. E. M. Hedges. 2013. Hydroxyproline dating: experiments on the $\mathrm{C}$ analysis of contaminated and low-collagen bones. Radiocarbon 55(2):698-708. doi:10.1017/s00338222000 57854 . 
Marom, A., J. S. O. Mccullagh, T. F. G. Higham, A. A. Sinitsyn, and R. E. M. Hedges. 2012. Single amino acid radiocarbon dating of Upper Paleolithic modern humans. Proceedings of the National Academy of Sciences of the USA 109(18):6878-6881. doi:10.1073/pnas.1116328109.

McBrearty, S., and A. S. Brooks. 2000. The revolution that wasn't: a new interpretation of the origin of modern human behavior. Journal of Human Evolution 39(5):453-563. doi:10.1006/jhev.2000.0435.

Mellars, P. 1989. Major issues in the emergence of modern humans. Current Anthropology 30(3):349-385. doi:10.1086/203755.

1991. Cognitive changes and the emergence of modern humans in Europe. Cambridge Archaeological Journal 1(1):63. doi:10.1017/s0959774300000251. 2005. The impossible coincidence: a single-species model for the origins of modern human behavior in Europe. Evolutionary Anthropology: Issues, News, and Reviews 14(1):12-27. doi:10.1002/evan.20037.

Michel, V., H. Valladas, G. Shen, W. Wang, J.-X. Zhao, C.-C. Shen, P. Valensi, and C. J. Bae. 2016. The earliest modern Homo sapiens in China? Journal of Human Evolution 101:101-104.

Moorjani, P., S. Sankararaman, Q. Fu, M. Przeworski, N. Patterson, and D. Reich. 2016. A genetic method for dating ancient genomes provides a direct estimate of human generation interval in the last 45,000 years. Proceeding of the National Academy of Sciences of the USA 113(20):5652-5657. doi:10.1073/pnas.1514696113.

Pettitt, P. B., and N. O. Bader. 2000. Direct AMS radiocarbon dates for the Sungir Mid Upper Palaeolithic burials. Antiauity 74(284):269-270. doi:10.1017 /s0003598x00059196.

Pleurdeau, D., M.-H. Moncel, R. Pinhasi, R. Yeshurun, T. Higham, T. Agapishvili, M. Bokeria, et al. 2016. Bondi Cave and the Middle-Upper Palaeolithic transition in western Georgia (south Caucasus). Quaternary Science Re views 146:77-98.

Reimer, P. J., M. G. L. Baillie, E. Bard, A. Bayliss, J. W. Beck, P. G. Blackwell, C. Bronk Ramsey, et al. 2009. IntCal09 and Marine09 radiocarbon age calibration curves, 0-50,000 years cal BP. Radiocarbon 51(4):1111-1150. doi:10 $.1017 /$ S0033822200034202.

Reimer, P. J., E. Bard, A. Bayliss, J. W. Beck, P. G. Blackwell, C. Bronk Ramsey, C. E. Buck, et al. 2013. IntCal13 and Marine13 radiocarbon age calibration curves 0-50,000 years cal BP. Radiocarbon 55(4):1869-1887. doi:10.2458/azu _js_rc.55.16947.
Rolandi, G., F. Bellucci, M. T. Heizler, H. E. Belkin, and B. De Vivo. 2003. Tectonic controls on the genesis of Ignimbrites from the Campanian volcanic zone, southern Italy. Mineralogy and Petrology 79(1-2):3-31. doi:10.1007 /s00710-003-0014-4.

Sinitsyn, A. A. 2003a. The most ancient sites of Kostenki in the context of the Initial Upper Paleolithic of northern Eurasia. In The chronology of the Aurignacian and of the transitional technocomplexes: dating, stratigraphies, cultural implications. J. Zilhão and F. d'Errico, eds. Pp. 89-107. Lisbon, Portugal: Instituto Português de Arqueologia.

2003b. A Palaeolithic "Pompeii" at Kostenki, Russia. Antiquity 77 (295):9-14. doi:10.1017/S0003598X00061299.

2004. Les sépultures de Kostienki: chronologie, attribution culturelle, rite funéraire. In La Spiritualité: Actes du Colloque de la Commission de l'UISPP, Liège, 2003. M. Otte, ed. Pp. 237-244. Liège, Belgium: Études et Recherches Archéologiques de l'Université de Liège.

Sinitsyn, A. A., and J. F. Hoffecker. 2006. Radiocarbon dating and chronology of the early Upper Paleolithic at Kostenki. Quaternary International 152153:164-174. doi:10.1016/j.quaint.2005.12.007.

Sutikna, T., M. W. Tocheri, M. J. Morwood, E. W. Saptomo, Jatmiko, R. Due Awe, S. Wasisto, et al. 2016. Revised stratigraphy and chronology for Homo floresiensis at Liang Bua in Indonesia. Nature 532(7599):366-369. doi:10.1038 /nature17179.

Tushabramishvili, N., D. Pleurdeau, M.-H. Moncel, T. Agapishvili, A. Vekua, M. Bukhsianidze, B. Maureille, et al. 2012. Human remains from a new Upper Pleistocene sequence in Bondi Cave (western Georgia). Iournal of Human Evolution 62(1):179-185. doi:10.1016/j.jhevol.2011.11.001.

Wood, R. E., C. Bronk Ramsey, and T. F. G. Higham. 2010. Refining background corrections for radiocarbon dating of bone collagen at ORAU. Radiocarbon 52(2):600-611. doi:10.1017/s003382220004563x.

Wood, R. E., K. Douka, P. Boscato, P. Haesaerts, A. Sinitsyn, and T. F. G. Higham. 2012. Testing the ABOx-SC method: dating known-age charcoals associated with the Campanian Ignimbrite. Quaternary Geochronology 9:1626. doi:10.1016/j.quageo.2012.02.003.

Zilhão, J., D. E. Angelucci, E. Badal-Garcia, F. d‘Errico, F. Daniel, L. Dayet, K. Douka, et al. 2010. Symbolic use of marine shells and mineral pigments by Iberian Neandertals. Proceedings of the National Academy of Sciences of the USA 107(3):1023-1028. doi:10.1073/pnas.0914088107. 